\title{
THROUGHFALL PATTERNS AND CANOPY COVER INDICES IN A HIGHLY HETEROGENEOUS FOREST
}

João Macedo Sá ${ }^{1}$, Debora Yumi de Oliveira ${ }^{2}$, Joana Giglio ${ }^{2}$, Masato Kobiyama ${ }^{3}$, and Pedro Luiz Borges Chaffe ${ }^{2}$

${ }^{1}$ Universidade Federal de Santa Catarina Centro Tecnologico

${ }^{2}$ Universidade Federal de Santa Catarina

${ }^{3}$ Federal University of Rio Grande do Sul

May 26, 2020

\begin{abstract}
While rainfall interception controls how much water will be ultimately available for many ecological functions, it is not well understood how canopy structure controls the spatial and temporal distribution of throughfall inside forests. Specially in subtropical and highly heterogenous forests, such as the Atlantic Forest in Brazil, rainfall interception has been only timidly studied. In this paper we investigated how the spatial and temporal variations of throughfall are controlled by the canopy structure. Throughfall spatial variability was measured for a period of over a year using 28 throughfall gauges uniformly distributed in a $28 \mathrm{~m}^{2}$ Atlantic Forest plot in Southern Brazil. We proposed the use of the number of overlapping crowns (NOC) as a measure of canopy structure and compared it to the commonly adopted Canopy Cover Fraction (CCF) and the Leaf Area Index (LAI). Locations with a higher CCF, LAI and NOC have a large throughfall variability among rainfall events, even though throughfall amounts could not be directly related to those canopy cover indices. This result implies that the throughfall variability is due to preferential pathways created by the overlapping canopy layers. Additionally, throughfall spatial distribution for periods with lower amounts of gross rainfall is similar to NOC, suggesting that for smaller events the canopy storage capacity is the major control of the amount of rainfall reaching the soil.
\end{abstract}

\section{Hosted file}

HyP_20200525.pdf available at https://authorea.com/users/326455/articles/454289-throughfallpatterns-and-canopy-cover-indices-in-a-highly-heterogeneous-forest 

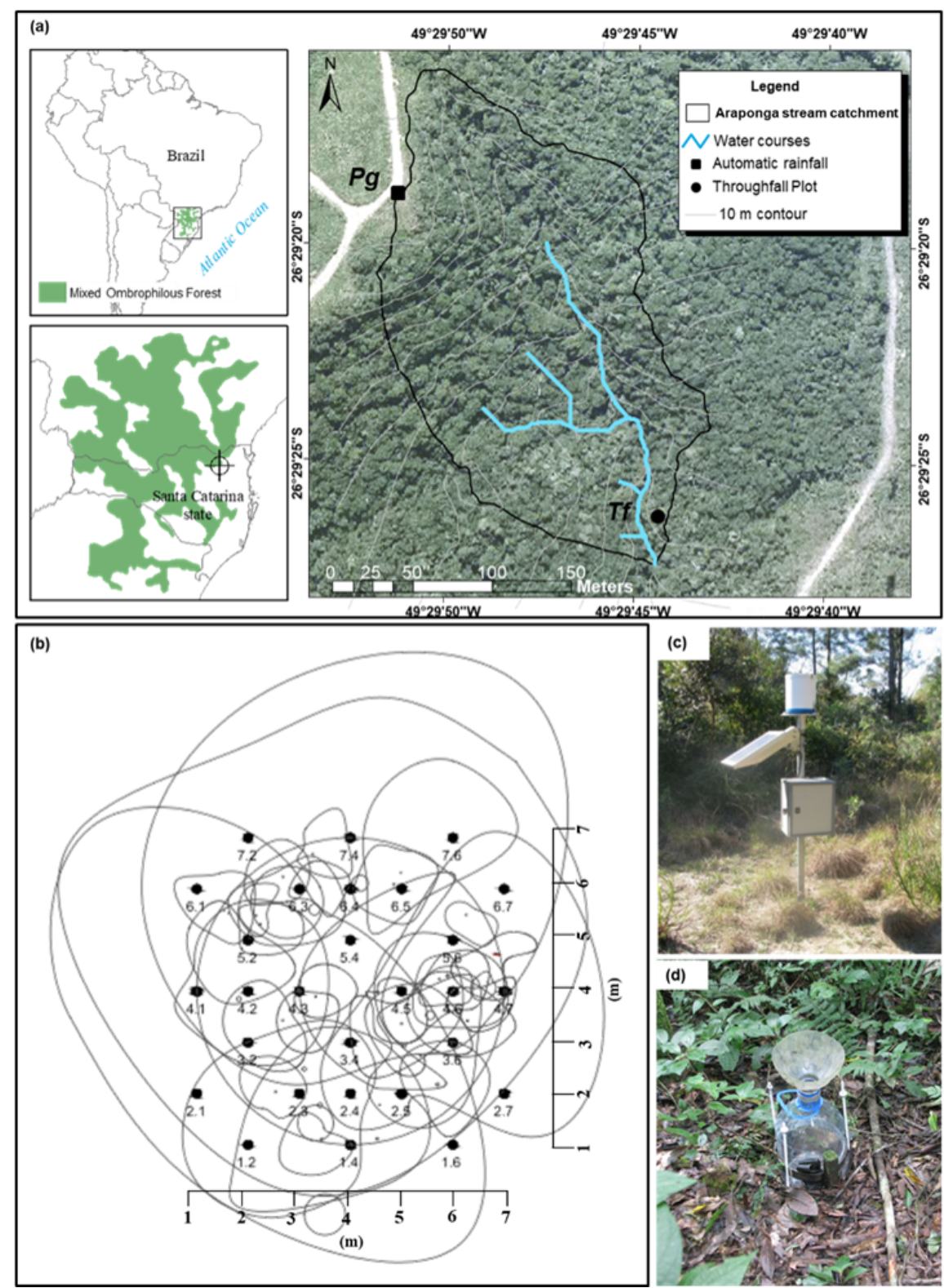

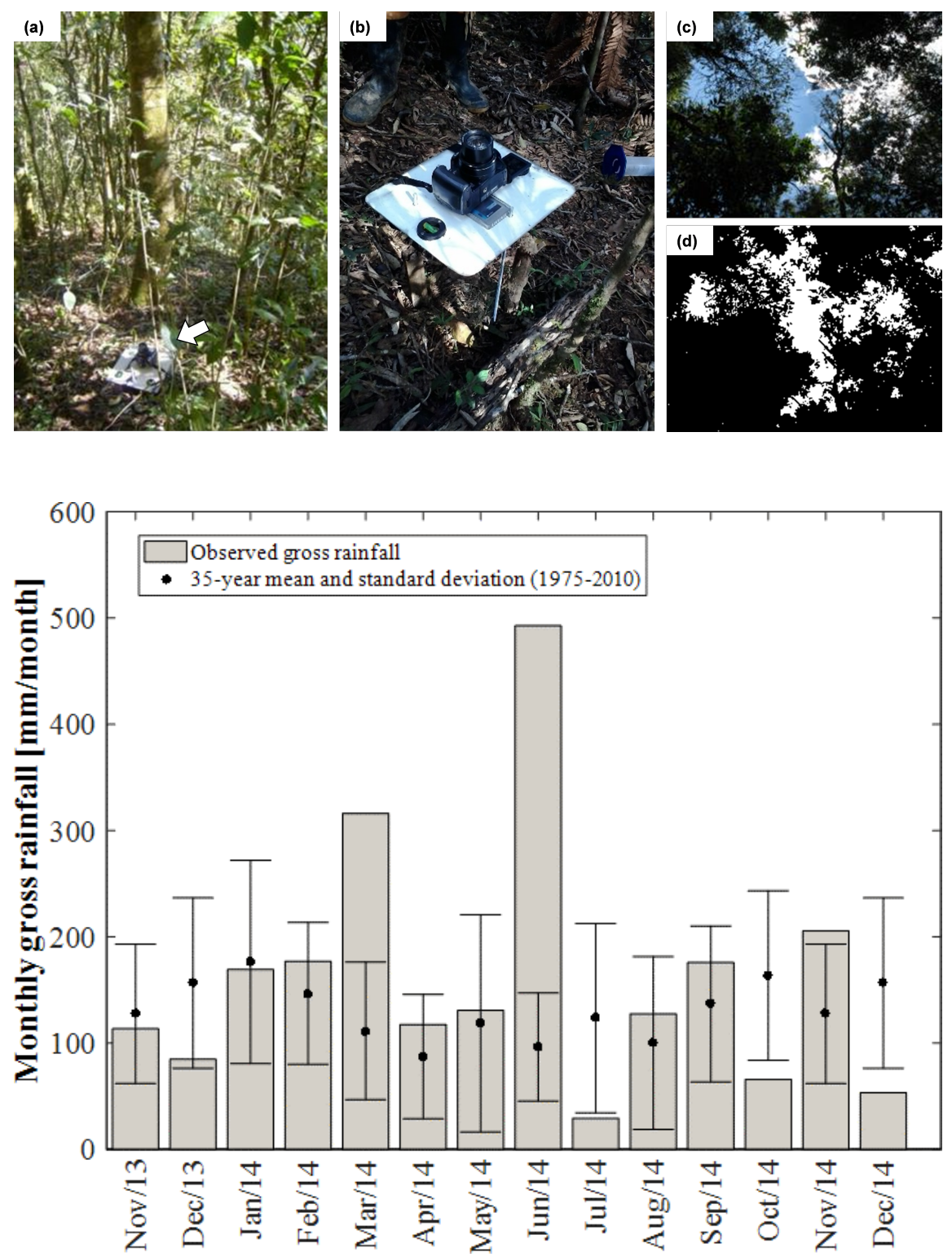

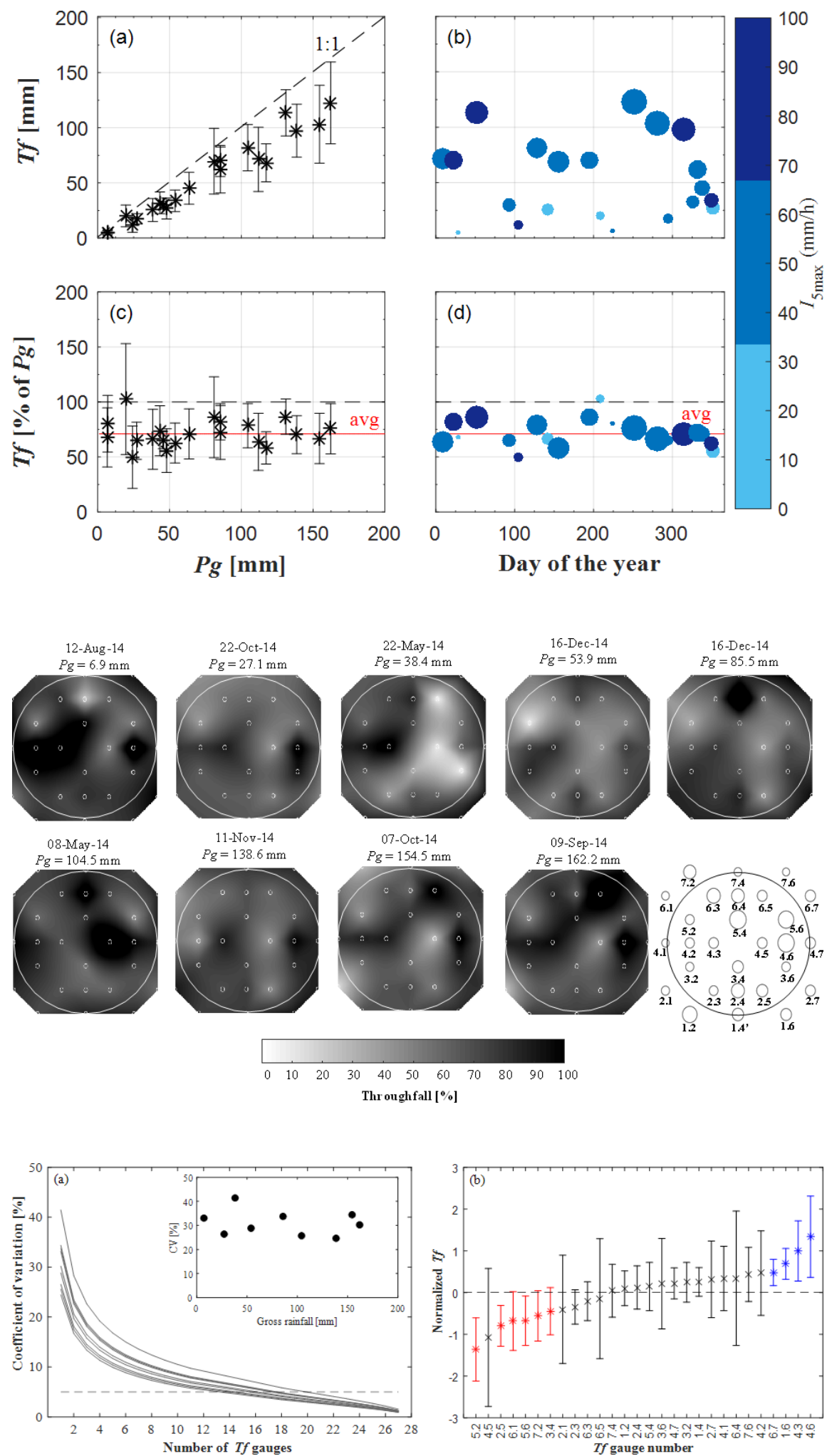

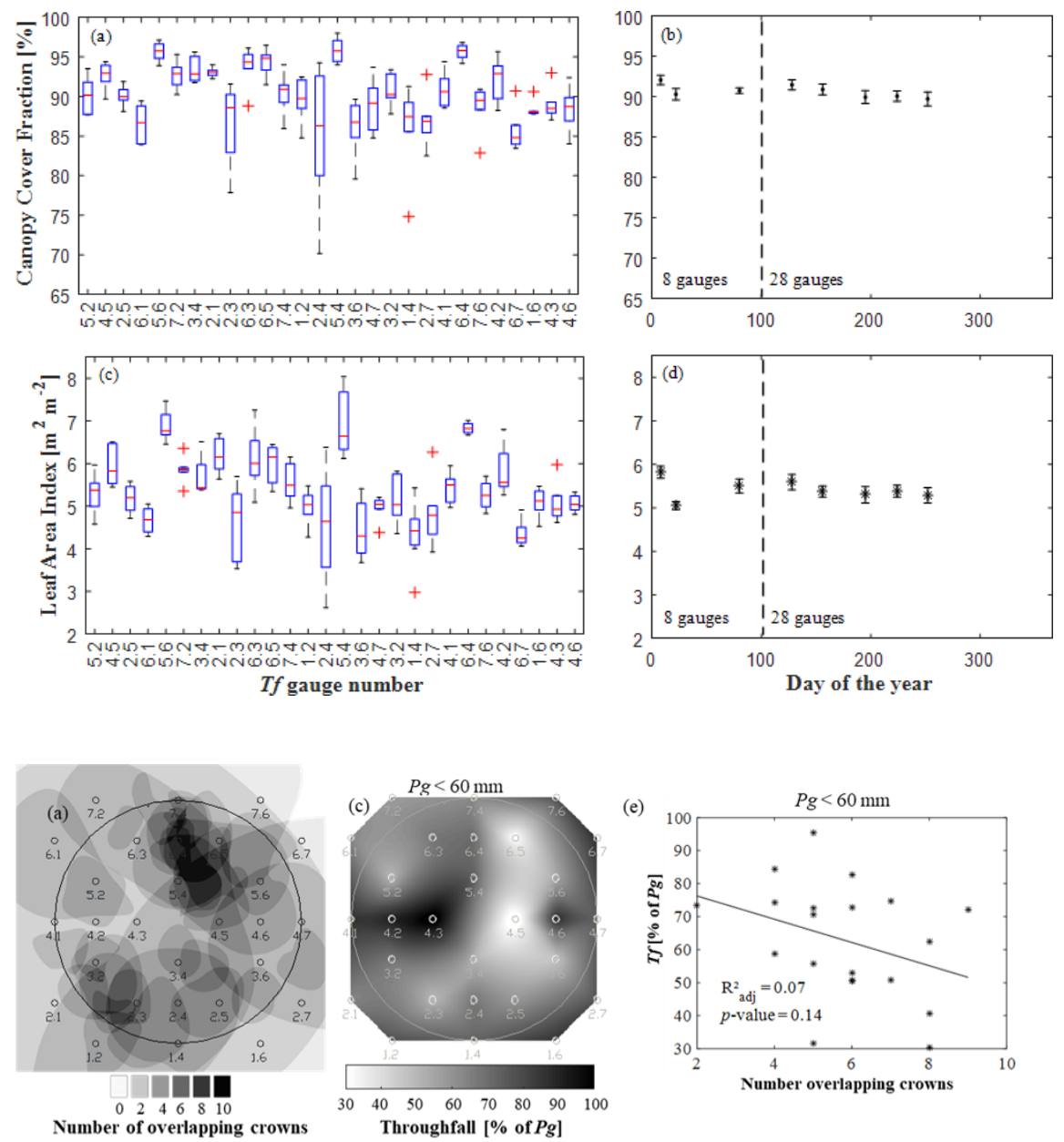

Number of overlapping crowns
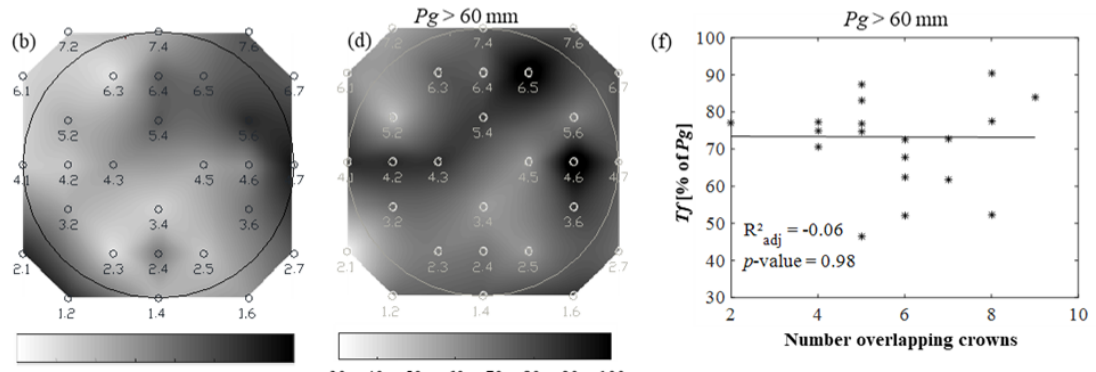

\begin{tabular}{llllllll}
\hline 0 & 0.5 & 1.0 & 1.5 & 2.0 & 2.5 & 3.0 & 3.5
\end{tabular}

Canopy storage capacity [mm]

Throughfall [\% of $\mathrm{Pg}$ ]
